\title{
Reasons for parasuicide among patients admitted to Tshilidzini Hospital, Limpopo Province: A qualitative study
}

\author{
M Obida, ${ }^{1}$ MD, MMed (Fam Med); C Clark, ${ }^{1}$ MD, MMed (Fam Med); \\ I Govender, ${ }^{2} \mathrm{MB}$ ChB, MBA, MMed (Fam Med), AUDOH, FCFP, Dip HIV/AIDS \\ ${ }^{1}$ Department of Family Medicine and Primary Care, Tshilidzini Hospital, Thulamela, South Africa \\ ${ }^{2}$ University of Limpopo, Medunsa campus, Pretoria, South Africa
}

Corresponding author: I Govender (indiran.govender@gmail.com)

\begin{abstract}
Background. Suicide and suicide attempts are commonly encountered in primary healthcare. To manage them competently and in a nonjudgmental manner, health workers require an in-depth understanding of this problem.

Objective. To determine the reasons for suicide attempts among patients admitted at Tshilidzini Hospital.

Method. A descriptive qualitative study used an unstructured in-depth interview for data collection, with 10 purposively selected participants. The data were analysed thematically.

Results. The participants gave the following reasons for their suicidal acts: poverty, unemployment and its associated financial difficulties; domestic violence; interpersonal conflicts; HIV/AIDS-related problems; maternal death; depression; hallucinations; and accusations of witchcraft. These factors interacted, producing feelings of hopelessness, worthlessness and lack of meaning in life, thereby driving the individual to resort to desperate measures. The choice of method for each suicide attempt was influenced by availability, knowledge, experience and the seriousness of intent to die. Conclusion. This study supports the idea that a suicidal act is a complex phenomenon arising in an distinctive way in each individual, based on the interplay of various factors.
\end{abstract}

S Afr J Psych 2013;19(4):222-225. DOI:10.7196/SAJP.452

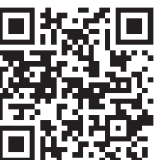

Suicide and suicide attempts are commonly encountered in primary healthcare. The 1999 World Health Organization Regional Office for Europe (WHO/EURO) Multicentre Study ${ }^{[1]}$ is the largest multicentre study with specific data about attempted suicide globally. It estimated that the average European rate for attempted suicide in persons aged 15 years and above was 140:100 000 for males and 193:100 000 for females. Parasuicide rates increased in the last 50 years $^{[2]}$ and parasuicide has become an increasingly common response to emotional distress among young people. Suicide and parasuicide rates are important markers of the mental health of a population. ${ }^{[3]}$ In South Africa (SA), there is a higher risk for suicide attempts among people who are younger, female and less educated. ${ }^{[4]}$

Studies on suicide and attempted suicide are few in Africa. Madu and Matla ${ }^{[2]}$ showed that more females than males attempt suicide in Africa, except in Nigeria, Egypt, Ethiopia and Uganda. The overall suicide rate in SA in 1990 was 17.2:100 000 of the population, above the global average of 16:100 000. ${ }^{[5]}$ Mhlongo and Peltzer ${ }^{[3]}$ singled out AIDS phobia, academic failure and teenage pregnancy as reasons for suicide among the youths referred to their practice. In a 2004 SA study, Mpiana et al. ${ }^{[4]}$ found that contributory factors to suicide attempts included emotional pain, unpleasant life feelings and thoughts of selfkilling with the expectation of dying and resting in peace.

Multicentre studies have found no differences in parasuicide epidemiology in the various regions of the world. ${ }^{[6]}$

A logistic regression model ${ }^{[7]}$ identified four significant predictors of repeat parasuicide: prior history of parasuicide; a history of depression; a history of schizophrenia; and poor physical health. A risk factor scale constructed from these variables showed that the risk of repeat parasuicide increases as the number of risk factors increases. Having had a previous parasucuide incident increases the likelihood of attempting suicide by 100 times in the year following the episode, compared with the general population. ${ }^{[8]}$ Women appear to have higher rates of parasuicide than men. Younger age groups of both genders are at higher risk, with female parasuicides being younger than males in many studies. ${ }^{[9]}$ In SA age, race and city play independent roles in sex-specific suicide rates ${ }^{[10]}$ and there is a need for specific research into suicide attempts in different SA cities. Despite some common trends across SA cities, there are variations in the magnitude and distribution of suicide mortality across race and sex groups and in the suicide method. ${ }^{[11]}$ Factors contributing to suicide attempts include marital status, unemployment, a recent change in living situation, mental disorders, and a previous parasuicide incident. ${ }^{[12]}$ There is also a strong link between previous traumatic events and suicidal behaviour. ${ }^{[13]}$

At Tshilidzini Hospital in SA's Limpopo Province in 2003, it was found that out of a total of 225 autopsies due to unnatural causes, 52 (23\%) were suicide. This suicide rate was above the national average of $8-10 \%$ for general hospitals. Determining the reasons for suicide attempts may help the hospital train doctors, social workers and psychologists to manage this problem better, and help the hospital conduct community outreach via the clinics. The findings of this study will be presented to all hospital staff.

\section{Objective}

To determine the reasons for suicide attempts among patients admitted to Tshilidzini Hospital in the Thulamela municipality of the Vhembe District in Limpopo. 


\section{Methods}

A qualitative study used a face-to-face, unstructured, in-depth interview to collect data from 10 purposively selected participants. Qualitative research is holistic, allowing participants to give form and meaning to their experiences in their own words and thus to provide rich descriptive detail. ${ }^{[14]}$ It was considered well-suited for this study, as the issues encountered were subjective, sensitive and very personal and could not be fully understood by quantitative means. ${ }^{[15]}$ The reasons for suicide attempts were investigated to gain an in-depth understanding of the phenomenon of attempted suicide.

We included all patients aged 16 years and older who were admitted following attempted suicide between 17 April and 3 July 2007. Participants who met the inclusion criteria, could provide rich information on their reasons for attempting suicide and were ready to talk about their suicide attempt were purposively selected. All interviews were conducted in Tshivenda by a research assistant, except one which was conducted in English.

The opening exploratory question was: 'You seemingly tried to kill yourself; can you describe for me what happened?' This question was found to be open and inviting, offering participants the chance to give a detailed account of the events leading to their suicide attempt. Probing questions were introduced in response to the participant's statement, to clarify and expand on certain issues. Reflective summaries were used to confirm and validate what the participant had said.

The interviews were audio recorded and fieldnotes were taken. Family genograms were drawn with each participant to understand their social and family background. The interviews were transcribed verbatim and then translated into English. Triangulation was used to ensure the study's validity and reliability. Triangulation conducted among reliable sources was used to recontextualise the findings, to formulate ideas, and to understand the reasons for the suicide attempt.

Data were analysed thematically. Tesch's descriptive method of open coding was used to analyse the interview transcripts and the fieldnotes. ${ }^{[16]}$ Categories, patterns and themes were sorted manually according to the theoretical framework described by Duxbury. ${ }^{[17]}$ Subsequently, an overall thematic description of the patients' experiences, reasons for the attempted suicide and contributing factors were obtained.

The 10 participants were aged between 17 and 41 years. Eight were female. Four were secondary school students and the rest unemployed. Six participants were married and 8 belonged to the Christian faith, while the others did not mention any religious affiliation.

\section{Ethics approval}

Ethics approval was obtained from the Ethics and Publications Committee of the University of Limpopo (Medunsa Campus): Clearance Certificate No. MP134/2005. Written permissions were also obtained from the Limpopo Department of Health and Social Development and Tshilidzini Hospital management. Written informed consent was obtained from all participants before conducting the interviews, except in the case of one 17-year-old participant who gave assent and whose mother gave consent.

\section{Results}

\section{Method of suicide attempt}

Five participants attempted suicide by ingesting what they considered to be poisons, three used hanging, one attempted drowning and the other attempted to set the house alight with herself and her children inside. The choice of method was influenced by several factors: knowledge of the mechanism and perceived duration of action to achieve the intended action, availability and level of motivation to die. This is demonstrated by such statements as:

- 'I thought paraffin was fast, that if I drank it, it would serve the purpose faster.'

- 'I took pills. I looked around and found there was nothing else I could use that would be instrumental in killing me successfully'.

- 'If one hangs herself well with a rope that is tied well, by the time people come one would be dead.'

\section{Reasons given for suicide attempts}

The following emerged from the interviews as participants named their reasons for committing suicide.

\section{Financial difficulties and lack of support}

Most participants mentioned financial difficulties and lack of support as the main reasons for their suicide attempt. Most of them had to look after families with limited resources:

- 'We stay alone, just the two of us using this R200 child grant; we don't work at all.'

- 'It is difficult for me to look at my children suffer while I am still alive. I feel it is difficult for me. I have nothing, I am poor.'

- 'I went on to open the kitchen unit ... also the fridge, and I found that there were things that were lacking and I saw I didn't have money'.

- 'There were debts ... I didn't have money.'

- 'I have no support.'

\section{Perceived benefits}

Some participants perceived that suicide would would give them a chance to: join their loved ones; stop suffering; rest in peace; avoid facing their problems again or solve the problem; or surrender care of children to relatives or the government. In one participant's words:

- 'I just thought that if I have killed myself it would be better; I would follow my mother.'

- 'I just feel that what I was trying to do yesterday, that is, killing myself, had it worked out well, I would have been dead and gotten some rest.'

Another participant felt that the government takes better care of orphaned children than children with parents. She felt that if she had died and left her children behind, the government would come in and take care of them better than when she was still alive, she said: 'I just think when I see other poor children who are suffering, I just think that they fare better when they are under the care of the government. I see the government takes better care of children who are orphaned and I think that when I am still alive, that kind of help cannot be offered to my children at all'.

Another participant who had separated from her spouse felt that the children would be free to go their father if she were dead: 'I just think that it is better that I kill myself so that this man can get his children. I would love to give him the kids but ... I find it hard to accept that he should take them. But now that I have nothing anymore and have no people to support me, I understand that for me to free them to go to their father, it would be better that I die first. If I die, the children can go without me seeing it. That is how I feel and think.' 


\section{Family dysfunction}

Most participants came from dysfunctional families characterised by intimate partner violence, lack of trust and rejection. They felt these factors contributed to their suicide attempt. Statements included:

- 'At one stage he beat me so badly that I was so swollen. I decided to go and report him to the police but he prevented me.'

- 'I thought it was better for me to kill her and kill myself because I still love her very much and even if I kill myself she will remain doing what she is doing.'

\section{Interpersonal relationship problems}

The study used the term 'interpersonal' to indicate relationships other than spousal relationships. One participant's suicide attempt was motivated by a strained, conflict-ridden relationship with her stepsister. She stated: 'I drank [paint] thinners because my younger sister is always insulting me and saying bad things to me. Whenever I touch something, she tells me I should not touch it because it belongs to her father.'

\section{Maternal death}

One negative life event which participants considered significant was the death of their mother. Half of the participants had lost their mothers at young ages and said that this had affected them negatively. For instance, one participant felt the suffering that led her to attempt suicide was a direct result of being an orphan: 'Maybe [I attempted suicide] because I am an orphan ... [Pause]. I grew up suffering because someone else's parent is not your parent. Someone's mother can never be your mother.'

\section{HIV/AIDS-related problems}

HIV/AIDS motivated one participant's suicide attempt. She cited her guilt about non-disclose to her partner; uncertainty about her child's HIV status; her failure to breastfeed; uncertainty about her life expectancy; and stigma. She said: 'I did not even breastfeed my baby. I am using milk formula. When [my partner] asks me why the baby is on milk formula, I just make up stories and tell him my breasts are sore ... I still have not told him anything and I feel I have a problem.'

\section{Psychiatric conditions}

Three participants specifically cited depression as a factor in their parasuicide. One said, 'My heart was always aching; I was always crying and having chest pains. I was always tired and sleepy and spent my days sleeping. I didn't even want to play with other children because I was very unhappy'.

One participant had a perceptual disorder and blamed hallucinations for her attempt at suicide: 'It was like I was seeing a vision of some old ladies wearing the makunda (traditional bangles) on their ankles coming to me, saying I should hang myself.'

\section{Witchcraft accusations}

One participant cited accusations of witchcraft as the reason for her suicide attempt: she felt that her husband suspected her of bewitching her mother-in-law. This disturbed her and she wondered how someone with whom she was sharing her life could accuse her of such an act. She said, 'These days it is not only older people who kill others; even young people kill, they can bewitch. I just feel that since I am the only young person in that family, they may be suspecting me of having killed their mother. They have just been accusing me of all this.'

\section{Contributing factors}

The factors which participants listed as contributing to their suicide attempts can be categorised as biological, psychological, social, environmental and cultural. These distinctions are simplistic as there is much overlapping, but are used for convenience of discussion. Fig. 1 illustrates the multifactorial reasons for attempted suicide, several of which will be at play in a given individual. The outer border of the model represents the various stressors/triggers/factors that, when they become intolerable, affect the individual's coping strategy, commonly leading to one or more emotional problems such as helplessness and depression, which may in turn lead to attempted or completed suicide.

This list of factors contributing to suicide is similar to those compiled in previous research. ${ }^{[18]}$ The hierarchy of suicide assessment model, as formulated by McDowel et al., ${ }^{[19]}$ also shows that there is gradual process leading towards attempted or completed suicide. There appears to be a final common pathway of unpleasant feelings that ultimately drive an individual to attempt or commit suicide. Hur et al. ${ }^{[20]}$ propose a model showing a common pathway of insomnia, depression and fatigue.

\section{Discussion}

Considering the participants' sociodemographic characteristics, and the findings of previous research on psychological distress in SA outpatients, ${ }^{[21]}$ it was not surprising that poverty and financial difficulties were central motivators for suicide attempts. When people struggle to share limited resources it leads to conflict, family dysfunction and lack of support, which may lead to suicidal behaviour among family members. It has been shown previously that populations living in deprived areas generally have higher suicide rates. ${ }^{[1]}$ Other themes that emerged were family dysfunction, intimate partner abuse, maternal death, interpersonal relationship problems and perceived benefits of suicide. This is in keeping with findings that being raised in a family prone to conflict is a risk factor for suicide attempts. ${ }^{[1]}$

HIV/AIDS was a significant contributor to one participant's attempt at suicide and her experience illustrated some of the typical emotional pain, stress, and turmoil many HIV/AIDS sufferers have to endure. ${ }^{[22]}$ Reportedly, the risk of suicidal behaviour is 36 times higher among HIV/AIDS patients than among the general population. ${ }^{[4]}$ Of note was one participant's perception that 'government takes better care of orphans'. The participant felt she had to kill herself to obtain care for her children. As far as we could establish, this has not previously been reported as a reason for a suicide attempt.

Cases in which men kill their spouses and themselves are welldocumented. Yet the view that it is 'better for me to kill her and kill myself because ... even if I kill myself she will remain doing what she is doing' is hard to understand as a reason for a suicide attempt and must be investigated quantitatively. Most participants found the interviewing process psychologically beneficial, in line with other studies. ${ }^{[23]}$

\section{Study limitations}

As a qualitative enquiry, the study's findings are not generalisable due to a small, non-representative sample size. Nevertheless, they provide insight into possible reasons for attempted suicide among this population. Similarly, using purposive sampling could have excluded some potential sources of information. Language was another limiting factor that could have resulted in loss of data during translation. 


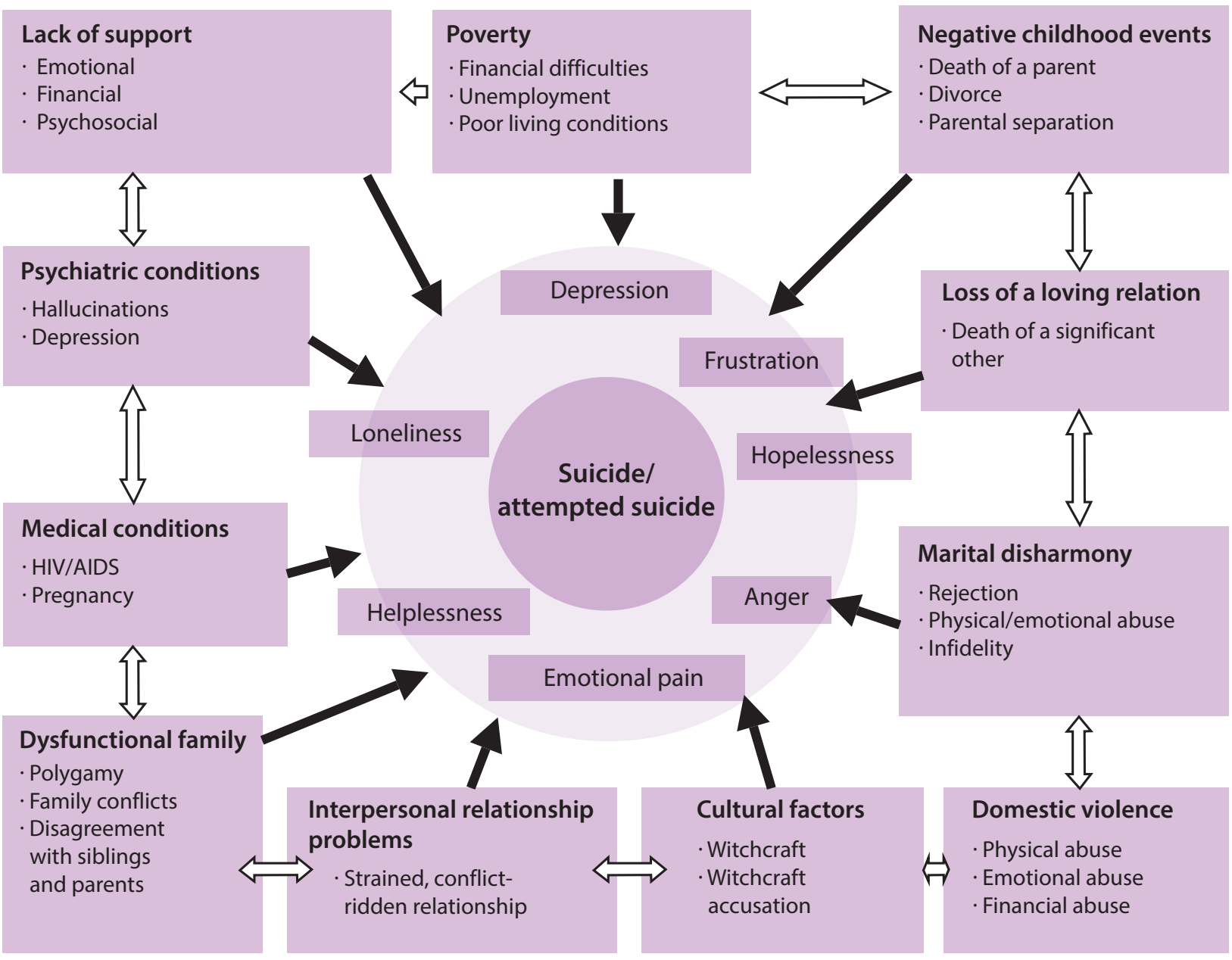

Fig. 1. Parasuicide/attempted suicide model.

\section{Conclusion}

Our research data are in keeping with recent research elsewhere in $\mathrm{SA}^{[10,11,13]}$ and support the idea that a suicidal act is a complex phenomenon arising in an individually distinctive way from the interplay of various factors.

\section{References}

1. Michel K, Ballinari P, Bille-Brahe U, et al. Methods used for parasuicide: Results of the WHO/EURO Multicentre Study on Parasuicide. Soc Psychiatry Psychiatr Epidemiol 2000;35(4):156-163. [http:// dx.doi.org/10.1007/s001270050198]

2. Madu SN, Matla MP. Family environmental factors as correlates for adolescent suicidal behaviors in the Limpopo Province of South Africa. Soc Behav Pers 2004;32(4):341-353. [http://dx.doi.org/10.2224/ sbp.2004.32.4.341]

3. Mhlongo T, Peltzer K. Parasuicide among youths in a general hospital in South Africa. Curationis 1999;22(2):72-76. [http://dx.doi.org/10.4102/curationis.v22i2.735]

4. Mpiana PM, Marincowitz GJO, Ragavan S, Malete N. 'Why I tried to kill myself' - an exploration of the factors contributing to suicide in the Waterburg District. SA Fam Pract 2004:46(7):21-25.

5. Schlebusch L. Depression and suicidal behavior. SA Fam Pract 2005;47(5):61-63.

6. Colman I, Newman SC, Schopflocher D, Bland RC, Dyck RJ. A multivariate study of predictors of repeat parasuicide. Acta Psychiatr Scand 2004;109(4):306-312. [http://dx.doi.org/10.1111/j.16000447.2003.00282.x]

7. Welch SS. A review of the literature on the epidemiology of parasucicde in the general opulation. Psychiatr Serv 2001;52(3):368-375. [http://dx.doi.org/10.1176/appi.ps.52.3.368]

8. Teo GS, Teh LC, Lim JH. (2008). Parasuicide and suicide: Demographic features and changing trend among cases in Hospital Sungai Bakap 2001-2005. Malaysian Journal of Psychiatry 2008;17(1):1-3.

9. Strydom MAA, Pretorius PJ, Joubert G. Depression and anxiety among Grade 11 and 12 learners attending schools in central Bloemfontein. South African Journal of Psychiatry 2012;18(3):84-88. [http://dx.doi.org/10.7196/SAJP.356]

10. Burrows S, Vaez M, Laflamme L. Sex-specific suicide mortality in the South African urban context:
The role of age, race, and geographical location. Scand J Public Health 2007;35(2):133-139. [http:// dx.doi.org/10.1080/14034940600975773]

11. Burrows S, Laflamme L. Suicide mortality in South Africa: A city-level comparison across sociodemographic groups. Soc Psychiatry Psychiatr Epidemiol 2006;41(2):108-114. [http://dx.doi. org/10.1007/s00127-005-0004-4]

12. Jenkins GR, Hale R, Papanastassiou M, Crawford MI, Tyrer P. Suicide rate 22 years after parasuicide: Cohort study. Br Med J 2002;16:325(7373):1155

13. Joe S, Stein DJ, Seedat S, Herman A, Williams DR. Non-fatal suicidal behavior among South Africans: Results from the South Africa Stress and Health Study. Soc Psychiatry Psychiatr Epidemiol 2008;43(6):454-461. [http://dx.doi.org/10.1007/s00127-008-0348-7]

14. Speziale HJ, Carpenter DJ. Qualitative Research in Nursing: Advancing the Humanistic Imperative 3rd ed. Philadelphia: Lippincott, Williams \& Wilkins, 2003.

15. Diekstra RFW. The epidemiology of suicide and parasuicide. Acta Psychiatr Scand Suppl 1993;371:920. [http://dx.doi.org/10.1111/j.1600-0447.1993.tb05368.x]

16. Creswell JW. Research Design: Qualitative, Quantitative, and Mixed Methods Approaches. Thousand Oaks, CA: SAGE Publications, 1994.

17. Duxbury J. An evaluation of staff and patient views of and strategies employed to manage inpatien aggression violence on one mental health unit: A pluralistic design. J Psychiatr Ment Health Nur 2002;9(3):325-337. [http://dx.doi.org/10.1046/j.1365-2850.2002.00497]

18. Dedić G, Djurdjević S, Golubović B. Psychological assessment of persons following suicide attempt by self-poisoning. Vojnosanit Pregl 2010;67(2):151-158. [http://dx.doi.org/10.2298/VSP1002151D]

19. wphysician. Mayo Clin Proc 2011;86(8):792-800. [http://dx.doi.org/10.4065/mcp.2011.0076]

20. Hur Y, Burri A, Spector TD. The genetic and environmental structure of the covariation among the symptoms of insomnia, fatigue, and depression in adult females. Twin Res Hum Genet 2012;15(6):720726. [http://dx.doi.org/10.1017/thg.2012.60]

21. Peltzer K, Pengpid S, Skaal L. Prevalence of psychological distress and associated factors in urban hospital outpatients in South Africa. South African Journal of Psychiatry 2012;18(1):10-15.

22. Govender RD, Schlebusch L. Hopelessness, depression and suicidal ideation in HIV-positive persons. South African Journal of Psychiatry 2012;18(1):16-21.

23. Hjelmeland $\mathrm{H}$, Nordvik $\mathrm{H}$, Bille-Brahe $\mathrm{U}$, et al. A cross-cultural study of suicide intent in parasuicide patients. Suicide Life Threat Behav 2000;30(4):295-303. [http://dx.doi.org/10.1111/j.1943-278X.2000. tb01096.x] 